\title{
Exílio e a retórica de violência divina em Jr 20:7-13
}

Exile and the Rhetoric of Divine Violence in Jer. 20:7-13

\author{
Lucas A. Iglesias Martins* \\ UNASP | São Paulo, Brasil \\ lucas.iglesias@usp.br
}

Resumo: $\mathrm{O}$ exílio Babilônico influenciou fortemente a linguagem da literatura profética. Dentre os livros proféticos nos quais observa-se esta linguagem de trauma e violência de forma mais viva, o livro de Jeremias merece atenção especial. $O$ presente artigo tratará sobre a retórica da violência divina nos lamentos do profeta Jeremias, especificamente o de Jr 20:7-13.

Palavras-chave: Exílio. Violência. Jeremias.

Abstract: The Babylonian exile has strongly influenced the prophetic literature language. Among the prophetic book where this language of trauma and violence can be seen in a vivid way, the book of Jeremiah deserves special attention. This paper will deal with the rhetoric of divine violence in Jeremiah's laments, specifically Jr 20:7-13.

Keywords: Exile. Violence. Jeremiah.

\section{Introdução}

No artigo intitulado "'Now you see me, now you don't!' Jeremiah and God", Philip S. Johnston observa que dentre as várias complexidades existentes no livro de Jeremias, encontra-se o retrato da percepção que o profeta tem sobre Deus. ${ }^{1}$ No primeiro capítulo do livro profético, divido em: (1) encontro inicial (v. 4-10); (2) visões (v. 1-16); e (3) exortação final (v. 17-19), observamos parte dessa percepção. A narrativa de Jeremias é inaugurada com uma revelação divina ao profeta. A realidade dessa experiência é dada como certa no relato e, aparentemente, sem qualquer explicação posterior. ${ }^{2}$

\footnotetext{
* Doutorando em Estudos Judaicos e Árabes pela Universidade de São Paulo (USP). Professor no UNASP.

1 JOHNSTON, 2014, p. 290.

${ }^{2} \mathrm{O}$ presente artigo não pretende discutir a historicidade do profeta Jeremias. Os problemas críticos que envolvem a relação entre a pessoa de Jeremias e o livro de Jeremias são muitos. Além disso, o presente artigo aborda o texto em sua forma final, sem discutir a autoria e data do livro. Assim, o livro retrata um profeta chamado Jeremias e sua interação intensa com $\mathrm{YHWH}$, algo que, de acordo com Johnston 
De acordo com Peter C. Craigie, esse relato dialoga com uma longa lista de relatos de vocação divina como, por exemplo, as de: Moisés, Samuel, Isaías, Ezequiel, Oséias, Amós, dentre outros. ${ }^{3}$ Ellen F. Davis afirma que Jeremias é o profeta que mais se assemelha a Moisés, primariamente, pela relação entre a resposta de Moisés ( $\hat{E} x$ 4:10) ao chamado divino e a resposta de Jeremias no v. $6^{4}$ :

"Eis que não sei falar" 5

No início do livro, constatamos asserções quanto ao relacionamento do profeta com Deus: (1) Deus conhece Jeremias antes mesmo de nascer e o constitui profeta às nações ( jovem e não saber falar; Deus rejeita o protesto, reafirma a comissão, e dá garantia da presença e do livramento (v. 7-8); (3) Deus toca a boca de Jeremias (v. 9) e expande sua comissão com quatro verbos associados à destruição e dois à construção (v. 10); (4) Nas duas visões dos v. 11-16 o chamado profético é confirmado; (5) Os v. 17-19 concluem com uma expansão dos temas iniciais (v. 7-9) de obediência, coragem e proteção divina, principalmente por intermédio da tripla metáfora de força no v. 19 (cidade fortificada, pilar de ferro, e muro de bronze). ${ }^{6}$

Contudo, apesar de toda garantida divina declarada ao profeta em sua vocação, temas, diálogos e linguagens peculiares de Jeremias, parecem não harmonizar com a percepção de segurança prometida na proteção divina. Em Jr 17:17, por exemplo, lemos:

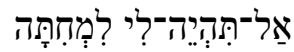

Não me sejas motivo de terror.

Apesar de no versículo seguinte (v. 18) Jeremias retratar a Deus como seu "refúgio", o discurso do profeta carrega a inconstância e a possibilidade desse mesmo Deus ser para ele, "motivo de terror". Concordando com a afirmação inicial de Johnston, Ellen F. Davis pontua:

De uma perspectiva teológica, o aspecto mais visceralmente confuso e perturbador do livro é que diferentes retratos de YHWH emergem sem uma orientação clara sobre qual deles

(2014, p. 291), foi suficiente para que os editores finais o vissem como um retrato autêntico de profecia e a tradição aceitá-lo como canônico.

${ }^{3}$ CRAIGIE, 1998, p. 12.

${ }^{4}$ DAVIS, 2014, p. 143.

${ }^{5}$ Todas as traduções para o português foram feitas pelo autor do artigo, mas serão apresentadas, também, suas versões de origem no rodapé. As traduções do hebraico para o português, salvo indicação contrária, são do autor deste artigo.

${ }^{6}$ JOHNSTON, 2014, p. 292. 


\section{Arquivo Maaravi}

poderia ser o fidedigno. Deus persistentemente envia profetas para advertir o povo contra desastres (7:25) e testar seus caminhos (6:27); todavia, YHWH é também Aquele que coloca pedras de tropeço no caminho (6:21) e os expõe a humilhação sexual pelos inimigos (13:26). O povo apela a YHWH como a "Esperança de Israel" (miqvēh yišrā'êl, 14:8; cf. 17:13), um fraseado que na verdade é um trocadilho; isto poderia igualmente ser traduzido por "tanque de água de Israel", especialmente pelo fato de aparecer aqui no contexto de um lamento ligado a uma profunda seca. Utilizando outra imagem de água, Jeremias censura aqueles que abandonam "a Fonte das águas correntes [ou 'vivas']" (17:13). Contudo, tais imagens positivas contrastam firmemente com a acusação de Jeremias direcionada à Face divina, de que $\mathrm{YHWH}$ é como um ribeiro que repentinamente se seca $(15: 18) .^{7}$

Diante dessa realidade, como compreender a aparente tensão existente entre os possíveis retratos de Deus em Jeremias?

Para Johnston, o exame dos lamentos do profeta é fundamental para compreender a experiência profética de Jeremias com YHWH. ${ }^{8}$ De acordo com Marvin Sweeney, Jeremias vive em constante conflito com YHWH, diferente de Isaías, que consistentemente se submete à vontade divina. ${ }^{9}$ Os conflitos de Jeremias com Deus são análogos aos seus conflitos com autoridades humanas como: sacerdotes de sua própria cidade-natal Anatote, os reis Jeoaquim e Zedequias, o sacerdote Pashur, e o povo de Jerusalém e Judá de forma geral. Ainda de acordo com Sweeney, 10 "O

7 "From a theological perspective, the most deeply confusing and disturbing aspect of the book is that very different pictures of YHWH emerge, with no clear guidance as to which of them might be reliable. God persistently sends prophets to warn the people against disaster (7:25) and to test their ways (6:27); yet YHWH is also the One who sets up stumbling blocks in their way (6:21) and exposes them to sexual humiliation by their enemies (13:26). The people appeal to YHWH as "the Hope of Israel" (miqvēh yišrā'êl, 14:8; cf. 17:13), a phrasing which is in fact a pun; it could equally be translated as "Israel's water-pool", especially since it appears here in the context of a lament over deep drought. Using another water image, Jeremiah decries those who forsake "the Fount of free-running [or 'living'] water" (17:13). Yet those positive images contrast starkly with Jeremiah's pointed accusation to the divine Face, that YHWH is like a streambed suddenly gone dry (15:18)." (DAVIS, 2014, p. 145146).

8 JOHNSTON, 2014, p. 296-297.

9 SWEENEY, 2012, p. 299.

${ }^{10}$ SWEENEY, 2012, p. 299. 
conflito de Jeremias com YHWH culmina em seus lamentos, nos quais ele acusa YHWH de violá-lo e de embebedá-lo com a palavra divina; palavra essa que ele não quer falar ao seu povo, mas, ainda assim, deve."11

Dessa forma, o presente artigo examinará a imagem divina retratada nos lamentos apresentados pelo profeta Jeremias, com especial enfoque para o último dos lamentos do livro (Jr 20:7-13). Para isso, será feita uma breve análise da linguagem e dos temas presentes nos lamentos do livro, seguida de um estudo mais minucioso do último dos lamentos (Jr 20:7-13).

\section{Lamentos de Jeremias}

De acordo com Davis, ${ }^{12}$ dentre os livros proféticos, Jeremias é "certamente o mais confuso de se ler" ${ }^{13}$ Outros estudiosos chegam a considerá-lo até "ilegível". ${ }^{14}$ Dentre os vários fatores que contribuem para tal percepção, merecem destaque: (1) a variedade de estilos literários; (2) a linguagem de violência. ${ }^{15}$

A diversidade de estilos literários presentes em Jeremias é maior do que qualquer outro livro profético. Nele, encontramos, por exemplo: oráculos de juízo e de restauração, narrativas biográficas extensas, relatos de ação simbólica, trechos em prosa (sermões e epístolas) escritos com forte estilo retórico, diálogos entre o profeta e Deus, e lamentos proféticos em primeira pessoa. ${ }^{16}$

Os lamentos, ou "confissões de Jeremias", como são normalmente conhecidos, ${ }^{17}$ foram submetidos a exame minucioso no último século. A obra seminal de W. Baumgartner em 1917, as pesquisas de A. R. Diamond e K. M. O'Connor na década de 1980, e contribuições posteriores como de C. R. Seitz (1989) e outros, analisaram a linguagem peculiar dos lamentos do profeta.

11 "Jeremiah's conflict with YHWH comes to full culmination in his laments in which he charges YHWH with raping and impregnating him with the divine word that he does not want to speak to his people, but nevertheless must."

${ }^{12}$ DAVIS, 2014, p. 145.

13 "the most confusing to read".

14 PEELS, 2012, p. 99.

${ }^{15}$ Além da grande variedade literária citada acima, Eric Peels (2012, p. 99) menciona: (1) o número marcante de repetições (ex., "sermão do Templo" de Jr 7 e Jr 26; ou o anúncio de julgamento contra outros em Jr 6:22-24 e Jr 50:41-42), citações e alusões a passagens de outros livros da Bíblia; (2) a ausência de uma ordem cronológica; (3) a grande variedade de vozes que se intercambiam ao longo dos capítulos sem qualquer identificação; e (4) a considerável diferença entre a LXX e o TM (a LXX é 1/7 menor que o TM, e colocam as profecias contra as nações no meio do livro (após Jr 25:13), não no fim.

${ }^{16}$ DAVIS, 2014, p. 145.

${ }^{17}$ CARROLL, 1997, p. 46. 


\section{Arquivo Maaravi}

Embora a definição da quantidade de unidades de lamento presentes em Jr 11-20 não seja unânime entre a maioria dos estudiosos, ${ }^{18}$ muitas destas pesquisas exploraram uma característica distintiva destes lamentos: a relação existente entre os lamentos e os salmos de lamento. ${ }^{19}$

Jeremias proferiu polêmicas contra o templo de Jerusalém e sua ideologia deturpada por líderes corruptos. Como os Salmos são, dentre outras coisas, reflexos das reivindicações do templo de Jerusalém, muito provavelmente o profeta era familiar com a produção da liturgia do templo. O livro de Jeremias demonstra intimidade com as cadências, gêneros, e linguagem do saltério, embora o uso que Jeremias faz dos salmos parece ser distintivo. ${ }^{20}$

\subsection{Relação com os salmos de lamento}

Um dos grandes desenvolvimentos no estudo dos lamentos de Jeremias está relacionado à aplicação feita por Walter Baumgartner (1917) do método gattungsgeschichtlich, de Gunkel, no livro profético. ${ }^{21}$ A abordagem tradicional considerava as confissões como documentos biográficos da vida pessoal de Jeremias e, como resultado, uma exegese que valorizava aspectos psicológicos e emocionais se estabeleceu. ${ }^{22}$ Baumgartner foi um dos primeiros a indicar uma relação entre as confissões do profeta e o gênero "salmo de lamento". ${ }^{23}$ Para Diamond, com a análise feita por Baumgartner, é compreendido que o profeta fez uso de um gênero já estabelecido (provavelmente relacionada ao ambiente cúltico) e o adaptou para expressar suas experiências proféticas únicas ${ }^{24}$. Segundo Brueggemann ${ }^{25}$ : Com base nesta análise, Baumgartner é capaz de mostrar que Jeremias faz um uso imaginativo

${ }^{18}$ De acordo com Baumgartner e O'Connor são cinco unidades. Baumgartner inclui Jr 11:18-20, 21-23 (como uma única unidade), 15:15-21, 17:12-18, 18:18-23, e 20:10-13. Além disso ele adiciona poemas associados: Jr 12:1-6; 15:10-12; 20:7-9, 14-18. As unidade de lamento para O'Connor são: Jr 11:18-12:6; 15:10-21; 17:14-18; 18:18-23; 20:7-18. Para Diamond o número de unidades é oito. São elas: Jr 11:18-23; 12:1-6; 15:10-14; 15:15-21; 17:14-18; 18:18-23; 20:7-13; 20:14-18.

${ }^{19}$ JOHNSTON, 2014, p. 297.

${ }^{20}$ BRUEGGEMANN, 2007, p. 162.

${ }^{21}$ DIAMOND, 1987, p. 12.

22 PEELS, 2012, p. 112.

${ }^{23}$ BRUEGGEMANN, 2007, p. 163. Segundo Brueggemann, Baumgartner observa tanto nos lamentos do profeta como nos salmos os elementos: queixa, petição, motivação (o qual ele chama de "motifs"), garantia de ter sido ouvido, votos, e ação de graças.

${ }^{24}$ DIAMOND, 1987, p. 12.

${ }^{25}$ BRUEGGEMANN, 2007, p. 163. 
do gênero, um uso possível unicamente por Jeremias ter sido nutrido e moldado por tais cadências comuns há muito estabelecidas. ${ }^{26}$

Blenkinsopp, afirmando ser inapropriado categorizar os lamentos de Jeremias como "confissões" pelo fato de não serem autobiograficamente explícitos ou reveladores, pontua:

Como muitos dos monólogos de Jó, eles [os lamentos], ao invés disso, denunciam estreita afinidade em estilo e linguagem com os salmos de lamentos individuais, uma circunstância que sugere precaução no uso delas como fontes de material biográfico. Ainda mais cautela existe para se argumentar quanto a uma forma litúrgica para um ambiente cúltico, no sentido de que Jeremias de fato transmitiu estes lamentos durante a adoração do templo como um oficial cúltico ou um autonomeado representante do povo. ${ }^{27}$

Independente de terem sido transmitidos no decurso da adoração do templo ou não, em Jr 20:7-13 podemos ver esta relação. ${ }^{28}$ Segundo J. A. Thompson, a relação pode inclusive ter paralelo com o evento relatado no trecho anterior, Jr 20:1-6. ${ }^{29}$ Ali, no ambiente da Casa do Senhor, Jeremias sofre nas mãos de Pashur, filho do sacerdote Imer (v. 1).

Além deste paralelo, aparentemente, o texto de Jr 20:7-13 faz uso deste gênero de salmo de lamento. ${ }^{30} \mathrm{O}$ lamento de Jeremias se inicia no v. 7 com uma dura acusação contra YHWH. O termo "persuadir", que trataremos em detalhes adiante, de acordo com Brueggemann, pode também ser lido como "estupro" ou "abuso sexual",

26 "On the basis of this analysis, Baumgartner is able to show that Jeremiah makes imaginative use of the genre, a use only possible because Jeremiah had been nurtured in and shaped by such long-established communal cadences."

27 "Like several of the monologues in Job, they betray rather close affinity in style and language with the psalms of individual lamentation, a circumstance that suggests caution in using them as biographical source material. Even more caution is in order in arguing from to a cultic setting, in the sense that Jeremiah actually delivered himself of these lamentations during temple worship as a cultic official or self-appointed representative of the people."

${ }^{28}$ Brueggemann observa que, claramente, a relação do livro de Jeremias com o Saltério não se restringe aos lamentos (2007, p. 166). Segundo ele, vemos por exemplo, na relação entre Jr 9:1-2 e S1 55:6-8, a inversão de fala do aflito. O livro de Jeremias, com liberdade artística transporta as palavras de tristeza proferidas por um israelita no salmo aos lábios de YHWH. (BLENKINSOPP, 1996, p. 134).

${ }^{29}$ THOMPSON, 1980, p. 457.

${ }^{30}$ ALLEN, 2008, p. 229. 
sugerindo assim que YHWH violou o profeta enviando-o para uma tarefa profética impossível. ${ }^{31} \mathrm{Um}$ paralelo próximo ao início do lamento de Jeremias (v. 7) ocorre no S1 44:13-14 (Heb. vv.14-15). ${ }^{32}$ Nos versículos, lemos:

Tu nos fazes opróbrio

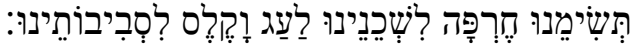

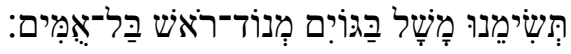

dos nossos vizinhos,

escárnio e zombaria aos que nos rodeiam.

Pões-nos por ditado entre as nações,

alvos de meneios de cabeça entre os povos.

Aqui, tal qual no lamento do profeta há uma queixa por conta de opróbrio, escárnio e zombaria por parte dos inimigos. A queixa dos v. 7-9 indica o peso da tarefa profética. Abruptamente, o poema muda de curso no v. 11 com uma declaração de confiança em YHWH. No v. 12 há mais uma petição para que YHWH decrete uma retribuição contra os inimigos do profeta. E por fim, no v. 13 observamos uma canção de ação de graças a YHWH, agora, em uma atmosfera de confiança.

Contudo, mesmo que existam semelhanças entre os salmos e os lamentos de Jeremias, não se pode negligenciar também suas divergências. Por exemplo, enquanto os inimigos nos salmos de lamento são mais difíceis de se definir, os inimigos de Jeremias são explícitos: seus familiares e irmãos. ${ }^{33} \mathrm{Ou}$ mesmo a própria afirmação de Baumgartner que nos lamentos de Jeremias há uma ênfase no ofício profético $^{34}$, algo sem paralelos nos salmos de lamento. ${ }^{35}$

Desde Baumgartner, obviamente, as discussões acerca dos lamentos de Jeremias têm alterado seu eixo. Com as obras de A. R. Diamond, Kathleen M. O'Connor, Mark Smith e Amy Kalmanofsky nota-se que as lamentações de Jeremias operam dentro do livro servindo a propósitos maiores, e com diferentes relações. ${ }^{36}$ Sobre uma dessas novas possibilidades de finalidade que trataremos em seguida.

\subsection{Lamentos de Jeremias e a linguagem de violência}

De acordo com Kathleen M. O'Connor, ${ }^{37}$ o caráter de Deus no livro de Jeremias é "múltiplo e instável". Imagens e metáforas de Deus no livro são confusas e se contradizem constantemente. Essa multiplicidade de representações dificulta o

\footnotetext{
${ }^{31}$ BRUEGGEMANN, 2007, p. 165.

${ }^{32}$ ALLEN, 2008, p. 230.

${ }^{33}$ AVIOZ, 2005, p. 433. (Jr 11:21-23; 12:6).

${ }^{34}$ Jr 11:21; 15:19; 17:15; 18:18,20.

${ }^{35}$ BAUMGARTNER, 2015, p. 50, 75.

${ }^{36}$ BRUEGGEMANN, 2007, p. 166.

${ }^{37}$ O'CONNOR, 1999, p. 387.
} 
retrato unilateral e a caracterização consistente de Deus, tornando-o assim, multifacetado. No decorrer do livro, notamos a construção de um retrato de um Deus como amoroso e compassivo simultâneo ao retrato dele como abusivo, como um marido violento, como um parceiro de aliança ofendido, como o executor de batalhas contra seu próprio povo, como um abusador de Judá, e por fim, como alguém que culpa as vítimas pela catástrofe sofrida. ${ }^{38}$

Do ponto de vista histórico-crítico, a questão é simples, tal caráter multifacetário é a consequência lógica do processo complexo de composição do livro, entendido como uma amalgamação de retalhos literários de períodos diferentes. Assim, não haveria qualquer necessidade de harmonização entre a realidade do Deus amoroso e compassivo e, ao mesmo tempo, violento.

Contudo, alguns estudos literários de Jeremias começaram a desafiar esta visão do livro como uma composição de partes sem harmonia..$^{39}$ Dentre eles, se destacam os estudos realizados por Brueggemann, Biddle, Diamond e O'Connor, e Stulman. ${ }^{40}$ O'Connor, por exemplo, em seu artigo The Tears of God and Divine Character in Jeremiah 2-9 estuda a caracterização divina nos ciclos poéticos de Jr 2-9, dando atenção particular ao Deus que chora em Jr 8:18-9:2.

Embora várias retratos divinos sejam complexos de se assimilar, talvez, um dos mais difíceis e que envolve grande parte das situações supracitadas é a imagem de um Deus violento. Mesmo que não seja constante, a Bíblia Hebraica, muitas vezes retrata a Deus como violento. ${ }^{41}$ Enquanto que por um lado, ignorar estes textos tem sido padrão em grande parte das comunidades religiosas, por outro lado, tais textos tem sido utilizados como validação de atitudes religiosas repressoras e truculentas.

Em seu artigo "God and Violence in the Prophets", L. Juliana Claassens ${ }^{42}$ se propõe a formular algumas estruturas hermenêuticas que auxiliem a compreensão da retórica de violência nestes textos. Na sequência, serão apresentadas duas delas: (1) Teoria do Trauma; (2) Violência e o contexto canônico.

${ }^{38} \mathrm{O}^{\prime} \mathrm{CONNOR}, 2010$, p. 37.

${ }^{39} \mathrm{O}^{\prime} \mathrm{CONNOR}, 1999$, p. 388.

${ }^{40}$ Walter Brueggemann, 'The Baruch Connection: Reflections on Jeremiah 43.1-7', JBL 113 (1994), p. 405-20; Mark Biddle, Polyphony and Symphony in Prophetic Literature: Rereading Jeremiah 7-20 (Macon, GA: Mercer University Press, 1996); A.R. Pete Diamond and Kathleen M. O'Connor, 'Unfaithful Passions: Coding Woman Coding Men in Jeremiah 2-3 (4:2)', Biblnt 4 (1996), pp. 280-310; Louis Stulman, 'Insiders and Outsiders in the Book of Jeremiah: Shifts in Symbolic Arrangement', JSOT 66 (1995), p. 65-85.

${ }^{41}$ O'CONNOR, 2010, p. 37.

${ }^{42}$ CLAASSENS, 2016, p. 334-349. 
Uma das mais recentes formas de se compreender a violência na retórica profética e sua relação com o contexto do exílio tem sido através da teoria do trauma como lente hermenêutica. ${ }^{43}$ Apropriando-se de insights desta teoria, O'Connor explica que os desastres destroem tudo que dá sentido à vida e oprimem os sentidos, proporcionando perda de memória, perda de linguagem e até torpor. Assim, a violência encontrada no livro de Jeremias poderia ser entendida como reflexo de memórias traumáticas. Dessa forma, a utilização desse tipo de linguagem seria um passo importante para que os sobreviventes possam reencontrar linguagem a fim de expressar os horrores da guerra.

Esta abordagem auxilia a compreensão, por exemplo, da linguagem de estupro utilizada em Jr 13. De acordo com O'Connor, a linguagem do estupro tem o propósito de capturar o trauma extremo que Judá experimentou, o horror da guerra retratado por meio da imagem de abuso de uma mulher abandonada. ${ }^{44}$

Além disso a teoria do trauma auxilia na compreensão da associação de Deus com a violência. ${ }^{45}$ Sweeney descreve como várias partes da Bíblia Hebraica apresentam possibilidades de sentido no envolvimento de Deus com o sofrimento, inclusive, de forma mais evidente, na invasão babilônica que destruiu Jerusalém. ${ }^{46}$ Deus é o causador do trauma de Israel.

Essa visão aparece associada à compreensão de que a violência do exílio tem uma explicação na tradição bíblica. Em Deuteronômio, ao Israel fazer um pacto com YHWH, dentre as maldições decorrentes da quebra da aliança estava prevista uma invasão por parte de um povo estrangeiro. Em Dt 28:49, lemos:

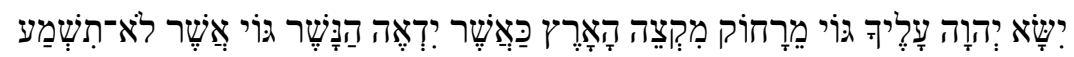
?ִשנjו:

O Senhor levantará contra ti uma nação de longe, da extremidade da terra virá, como voo impetuoso de águia, nação cuja língua não entenderás.

Essa nação viria e sitiaria a terra, não teria respeito, faria o povo passar fome, derrubaria os muros da cidade, dentre outras coisas. Tal invasão obviamente envolve a quebra da aliança feita entre Israel e seu Deus. Logo, o exílio, ao mesmo tempo que é consequência da quebra da aliança, é fruto da ação divina.

${ }^{43}$ CLAASSENS, 2016, p. 337.

${ }^{44}$ O'CONNOR, 2010, p. 37

${ }^{45}$ CLAASSENS, 2016, p. 338.

${ }^{46}$ SWEENEY, 2008, p. 103. 
A retórica de violência utilizada por Jeremias é mais comumente observada em situações de lamento. De acordo com Davis, com "honestidade brutal", Jeremias cria imagens inesquecíveis tanto de devastação e horror, como de restauração. ${ }^{47}$ Afinal, de um livro que trata de um horror ininterrupto, não se esperaria outra linguagem. Em seu livro Terror all around: Horror, Monsters, and Theology in the Book of Jeremiah, Amy Kalmanofsky chega a rotular alguns textos de Jeremias como "textos de horror". ${ }^{48}$ Utilizando os trabalhos teóricos de Noël Carrol e Julia Kristeva, ${ }^{49}$ Kalmanofsky demonstra como estes textos que envolvem o horror, muitas vezes tendo Deus como seu sujeito direto, alcançam seu impacto no leitor.

No trecho de Jr 20:7-13, por exemplo, veremos alguns destes componentes de violência e horror. Por exemplo, no v. 10, Jeremias é chamado de missāviv - "terror por todos os lados"), expressão que aparece também em 6:25; 45:5; 49:29. Aqui tal expressão parece ter relação direta com os v. 3-4 onde Pashur é chamado por Jeremias de "terror por todos os lados". Aparentemente, a murmuração dos inimigos de Jeremias envolve nomeá-lo, ironicamente, de "terror por todos os lados". Contudo, outros componentes ainda acrescentam à temática na perícope.

\section{Jeremias 20:7-13}

A perícope de Jr 20:7-13 está consolidada na integração de padrões unificadores de palavras e temas. ${ }^{50}$ Vemos aqui, por exemplo, palavras comuns a outros lamentos de

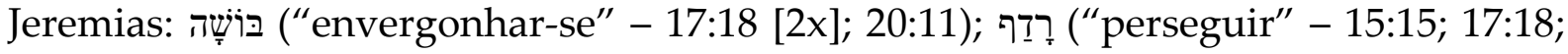
20:11); זָכַר ("lembrar" - 11:19; 15:15; 18:20); עָּרִ ("violento"; "poderoso" - 15:21; 20:11).

Uma possível estrutura deste lamento seria a que se segue. A. Queixa contra YHWH (v. 7-9); B. Queixa contra os inimigos (v.10); C. Confiança: YHWH está comigo (v. 11a); B'. Queda dos inimigos (v. 11b); C'. Confiança: YHWH vê o coração (v. 12a); B". Vingança sobre os inimigos (v. 12b); A'. Louvor a YHWH por libertação (v. 13)

Apesar da divisão fundamentada nas relações do profeta com Deus e com seus inimigos, aparentemente, o eixo de articulação do poema está no v. 10, cujo ’̣̣ ( $k \hat{\imath}$ "que"; "porque") inicial sinaliza a base para a compreensão dos v. 7-9. Essa partícula conjuntiva, repetida seis vezes no poema, não possui força retórica no centro da unidade, como normalmente é o caso. As duas ocorrências no v. 8 servem para colocá-lo à parte dos v. 7-9, mesmo que ainda se relacione tematicamente com eles. $\mathrm{O}$

47 DAVIS, 2014, p. 144.

${ }^{48} \mathrm{Jr}$ 4:5-6:30; 8:1-23; 13:15-27; 14:1-15:9; 18:13-17; 19:1-20:6; 23:9-22; 24:1-10; 30:5-9; 34:8-22; 46:1-51:64.

${ }^{49}$ Noël Carroll, The Philosophy of Horror or Paradoxes of the Heart. New York: Routledge, 1990; e Julia Kristeva. Powers of Horror: An Essay on Abjection. New York: Columbia University Press, 1982.

${ }^{50}$ DIAMOND, 1987, p. 101. 
v. 8 se torna, assim, uma transição entre o v. 7 e o v. 9. O כִ no início do v. 10 marca a transição da queixa contra $\mathrm{YHWH}$ para queixa contra os inimigos. E por fim, as três últimas conjunções (v. 11, 12,13) introduzem uma cláusula de motivo.

Se o v. 10 é pressuposto nos v. 7-9, ao mesmo tempo, ele é contrabalançado nos v. 1113 pelo agrupamento de elementos positivos. A situação humana do v. 10 é redefinida positivamente em termos divinos. ${ }^{51}$ Isso fica ainda mais claro devido ao vav adversativo que marca a transição no v. 11 (fenômeno comum nos salmos de lamento). Neste versículo, o vav indica a transição da queixa para a confiança, ponto de mudança na confissão do profeta. No v. 11 este vav aparece afixado ao nome de Deus, fenômeno que acontece outra vez no v. 12. Assim, o vav no v. 12 conecta v. 11a e v. $12 \mathrm{a}$, e carrega a asserção do v. $11 .^{52}$

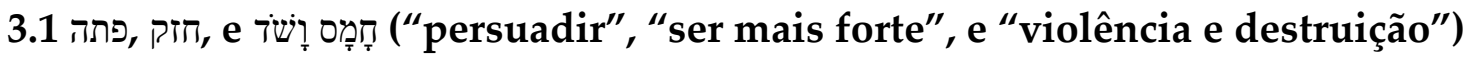

Clines e Gunn argumentam que um dos lamentos mais fortes do livro de Jeremias é o de 20:7-13 53 que começa com as palavras:

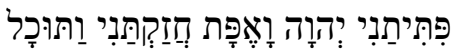

Persuadiste-me, ó Senhor, e persuadido fiquei; mais forte foste do que eu e prevaleceste.

Segundo eles, ligado à violência presente no lamento, o verbo פָָ (pātah "persuadir"), normalmente traduzido como "iludir", merece destaque. De acordo com alguns, a utilização deste verbo em conexão à sedução de uma mulher ( $\hat{E} x$ 22:15) serve para indicar o significado adequado para o verbo em Jr 20:7, fato que motiva a se traduzir o verbo como "seduzir". Abraham J. Heschel concorda com essa possibilidade de tradução. ${ }^{54}$ Em seu livro The Prophets, ele afirma:

A característica marcante do versículo é o uso de dois verbos: patah e hazak. O primeiro termo é usado na Bíblia no sentido especial de estar induzindo maldosamente uma mulher a concordar em ter relações sexuais prénupciais (Ex 22:16 [H. 22:15]; cf. Os 2:14 [H. 2:16]; Jó 31:9).

O segundo termo denota uma sujeição violenta de uma mulher a submeter-se a uma relação sexual extraconjugal, a qual é, desta forma, realizada contra a sua vontade (Dt

\footnotetext{
${ }^{51}$ ALLEN, 2008, p. 229.

${ }^{52}$ CRAIGIE, 1998, p. 272-273.

${ }^{53}$ CLINES; GUNN, 1978, p. 20.

${ }^{54}$ HESCHEL, 2001, p. 144.
} 


\section{Arquivo Maaravi}

22:15; cf. Jz 19:25; II Sm 13:11). O primeiro denota sedução e engodo; o segundo, estupro. Sedução é diferente de estupro no sentido em que não envolve violência. A mulher seduzida consentiu, embora seu consentimento tenha sido possível através de aliciamentos. As palavras usadas por Jeremias para descrever o impacto de Deus em sua vida são idênticas aos termos para sedução e estupro na terminologia legal da Bíblia. ${ }^{55}$

Somado a isso, alguns conectam a expressão (hām destruição") ao clamor de uma mulher abusada ${ }^{56}$. Para Craigie, embora seja possível esta tradução de Heschel principalmente quando as duas palavras aparecem juntas, em nenhum dos casos separadamente a conotação sexual é a mais comum. ${ }^{57}$

Clines e Gunn vão na mesma direção ao afirmar que tanto "prevalecer sobre") como hāmās wāsōd podem, obviamente, se referir a outros tipos de violência, enquanto a visão de que pātah se refere especificamente a sedução é baseada em uma única passagem, a de Ex 22:15. ${ }^{58}$ Por exemplo, em Pv 24:28 a ocorrência do verbo pātah não possui qualquer conotação sexual. Neste texto, lemos:

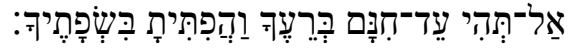

Ao que cuida em fazer o mal, mestre de intrigas lhe chamarão.

55 "The striking feature of the verse is the use of two verbs patah and hazak. The first term is used in the Bible and in the special sense of wrongfully inducing a woman to consent to prenuptial intercourse (Exod. 22:16 [H. 22:15]; cf. Hos. 2:14 [H. 2:16]; Job 31:9). The second term denotes the violent forcing of a woman to submit to extranuptial intercourse, which is thus performed against her will (Deut. 22:15; cf. Judg. 19:25; II Sam. 13:11). The first denotes seduction or enticement; the second, rape. Seduction is distinguished from rape in that it does not involve violence. The woman seduced has consented, although her consent may have been gained by allurements. The words used by Jeremiah to describe the impact of God upon his life are identical with terms for seduction and rape in the legal terminology of the Bible."

${ }^{56}$ CLINES; GUNN, 1978, p. 21.

${ }^{57}$ CRAIGIE, 1998, p. 273.

${ }^{58}$ CLINES; GUNN, 1978, p. 21. 
De acordo com Diamond à luz das possiblidades gerais de uso, é viável o teor sexual no uso destes verbos. ${ }^{59}$ Contudo, à luz do uso de pātah em qualquer outro lugar em relação aos profetas, não é plausível que a conotação sexual exerça influência dominante. ${ }^{60}$

Além disso, sobre a expressão hāmās wāsōd existem duas questões que podem auxiliar a compreensão da perícope: (1) Porque todas vez que Jeremias fala, ele tem que gritar hāmās wāasōd?; (2) A quem estas palavras são dirigidas quando ele as grita?

Três respostas tradicionalmente têm sido dadas: (1) Estas são acusações contra as opressões do rico sobre o pobre. Contudo, é difícil compreender o porquê de, por conta disso, ele servir de "escárnio todos os dias" (v. 7), ou em que sentido tal reação à sua mensagem o faria protestar que Deus "prevaleceu" (v. 7) sobre ele; (2) Estas são ameaças de juízo anunciadas contra a nação. Nesse caso, a "confissão" de Jr 20:7-13 se encaixa com as narrativas precedentes, nas quais há ameaça de mal contra Jerusalém e suas vilas (19:15), e é anunciado o cativeiro de Judá (20:4). Assim, Jeremias estaria dizendo que não importa quando proferisse um oráculo, seria uma palavra de juízo. Essa interpretação, contudo, não parece tão substanciosa, afinal, זָָׁ $\left(z \bar{a}^{\prime} a q\right.$ - "clamar") não é o termo apropriado para se introduzir tanto um discurso de julgamento como um oráculo de juízo. Pelo contrário, é um termo técnico para um clamor de súplica feito por um inocente contra seu opressor ${ }^{61}$. Ou, como afirma Carroll, um lamento que apresenta o protesto de sofrimento de um justo nas mãos de um injusto; ${ }^{62}$ (3) São as palavras convencionais para um clamor de auxílio. Jeremias estaria apelando a YHWH por libertação daqueles que o denunciavam e o perseguiam (20:10). Esta interpretação, estabelecida sobre o uso do verbo $z \bar{a}^{\prime} a q$, poderia ser aplicada de duas formas diferentes neste versículo: a) "Sempre quando abro minha boca, vejo que estou clamando a Deus por libertação dos meus opressores, pois tenho sido perseguido incessantemente". Dificilmente isto estaria

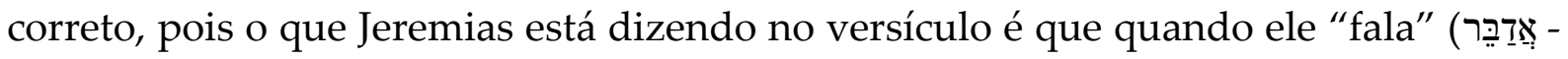
'ădabbēr), é especificamente uma "palavra de Deus" (דְבַר-יְָוָה - dabar YHWH), como sugerido pelo paralelismo entre v. 8a e v. 8b. Não significa que tudo o que ele diz é "violência e destruição"; b) "Quando digo a palavra de Deus, estou, ao mesmo tempo, apelando para auxílio futuro contra perseguidores, que irão, eu sei disso, me atacar por conta do que disse". Tal interpretação também é difícil, pois hāmās wāsōd não se refere normalmente ao clamor pronunciado em antecipação a um ataque, mas como um clamor de alguém já atacado ou por vingança.

\footnotetext{
${ }^{59}$ Para associações sexuais: Ex 22:15 (pātah); Dt 22:25; 2Sm 13:14 (hāaaq); Jr 13:22 (hāmās).

${ }^{60}$ DIAMOND, 1987, p. 112.

${ }^{61}$ CLINES; GUNN, 1978, p. 24.

${ }^{62}$ CARROLL, 1997, p. 46.
} 
Assim, de que modo deveríamos ler o pronunciamento do profeta no v. 8? Clines e Gunn sugerem uma opção alternativa a essas apontando a possibilidade de que “Violência e destruição!" deveria ser visto não somente como um clamor a Deus, mas também um clamor de protesto contra o próprio Deus. ${ }^{63}$

Jeremias estaria protestando contra Deus, pelo fato de Deus o constranger a falar suas palavras. Ironicamente, o único a quem ele pode clamar por auxílio é o próprio Deus. Seu clamor a Deus é, ao mesmo tempo, um protesto contra o próprio Deus. Com esta compreensão, a conexão de pensamento nos v. 7-9 se torna mais clara: "mais forte foste do que eu e prevaleceste"; "tenho de gritar e clamar: Violência e destruição!"; "fogo ardente [...]; não posso mais prevalecer".

Aparentemente, se esta expressão se referir a um apelo a Deus, ela antecipa a mudança positiva a YHWH nos v. 11-12. Assim, estaria destacando a tensão de um apelo contra Deus ao próprio Deus. Fazendo de Deus, tanto o causador como solucionador dos problemas. ${ }^{64}$

Percebemos que, aparentemente o tema central do lamento não envolve necessariamente a persuasão divina, mas sim, o tema da dominação sobre o profeta.

\subsection{Poder e domínio}

Essa tensão relacionada a poder e domínio, foco do lamento, é desenvolvida por uma

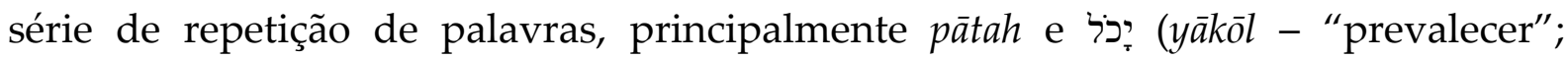
"permanecer"). ${ }^{65} \mathrm{O}$ profeta protesta contra a persuasão de Deus (v. 7), de quem ele não é capaz de prevalecer (v. 9). Os inimigos também esperam pela persuasão do profeta para que também possam prevalecer contra ele (v. 10). Estas conexões verbais provocam um certo paralelismo entre YHWH e os inimigos do profeta como forças opressivas.

Este paralelismo também é sustentado através da maneira que a seção de queixa (v. 7-10) é desenvolvida. Os problemas do profeta, tanto sofrer sob a palavra de Deus como sofrer sob a perseguição dos inimigos, são apresentados alternadamente e de maneira justaposta: v. 7a, 8a, e 9 associados ao sofrimento do profeta em relação a Deus; e v. $7 \mathrm{~b}, 8 \mathrm{~b}$, e 10 associados ao sofrimento do profeta em relação aos inimigos. ${ }^{66}$ Tal sugestão modificaria um pouco a proposta de estrutura inicial, principalmente no que tange aos v. 7-10.

Além disso, a alternância positivo-negativo associada ao verbo yākōl indiretamente auxilia o paralelismo. Enquanto YHWH é bem sucedido com o profeta, os inimigos

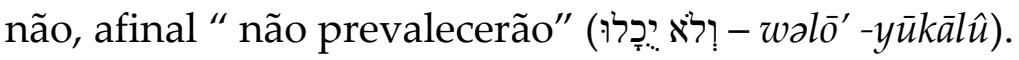

\footnotetext{
${ }^{63}$ CLINES; GUNN, 1978, p. 25.

${ }^{64}$ ALLEN, 2008, p. 230-231.

${ }^{65}$ DIAMOND, 1987, p. 101.

${ }^{66}$ DIAMOND, 1987, p. 103-104.
} 
E aqui chegamos ao ponto nevrálgico do lamento. É justamente a inabilidade do profeta em suportar $\mathrm{YHWH}$, cuja palavra se tornou poderosa de foram irresistível, que garante que a tentativa de persuasão por parte dos inimigos, falhará. O Senhor é

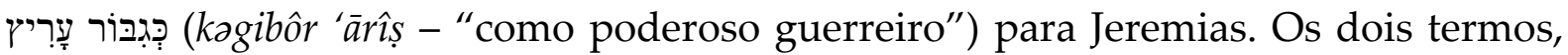
separadamente carregam detalhes curiosos. Enquanto רִּּ (gibôr - "guerreiro"; "herói") é um termo que aparece associado a ações salvíficas (Dt 10:17; Sl 24:8; Is 42:13; Sf 3:17), עָרִ ('ârị̂̂ - "violento"; "perverso") normalmente aparece associado a atos tiranos e perversos (S1 37:35; 54:5; 86:14; Jr 14:21).

O verbo pātah, que aparece no v. 7 duas vezes, como um par (piel-nifal) conhecido como ação-resultado, aparece outra vez na perícope no v. 10. Na primeira aparição, ele é usado como uma queixa contra $\mathrm{YHWH}$, enquanto que na segunda aparece como uma afirmação dos inimigos ("então prevaleceremos").

No v. 7, Deus persuade (pātah), é mais forte (hāaqaq) e prevalece (yākōl). No v. 10, os inimigos de Jeremias tem esperança de que o profeta seja persuadido ( $p \bar{a} t a h)$ para que eles prevaleçam (yākōl). Contudo, no v. 10 não vemos a aparição do verbo hăzaq ("ser forte"). Afinal, como é dito na sequência no v. 11, o Senhor é como "um poderosos guerreiro" para Jeremias. Logo, seus inimigos "não prevalecerão" (yākōl - v. 11). O paradoxo do lamento é que um dos motivos de Jeremias se queixar de Deus é justamente a solução para ele se ver livre dos seus inimigos, YHWH é mais forte. ${ }^{67}$ Aqui nota-se um eco à promessa feita ao profeta no seu chamado. Em Jr 1:19, lemos:

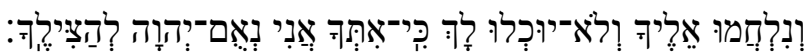

Lutarão contra ti, mas não prevalecerão; porque eu sou contigo, diz o Senhor, para te livrar.

Observamos exatamente o mesmo verbo para prevalecer ( $y \bar{a} k \bar{o} l$ ) utilizado ao longo de todo o lamento. Curiosamente, da mesma forma que Jr 1:19 finaliza com uma promessa de livramento (verbo נצל - nāṣal), em Jr 20:13, lemos:

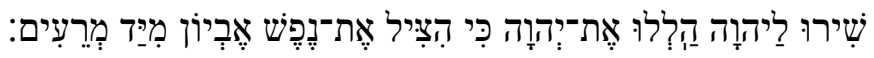

Cantai ao Senhor, louvai ao Senhor, pois livrou a vida do necessitado das mãos dos malfeitores.

O mesmo verbo (נצ-nāṣal), aparece agora aqui, em relação ao cumprimento da promessa divina no seu chamado. O chamado prometia fazer do profeta uma fortaleza. Seria fácil? Aparentemente, nem um pouco. Todavia, vemos neste lamento,

${ }^{67}$ CRAIGIE, 1998, p. 271. 
Deus reafirmando: "Confie na minha palavra". No v. 9, Jeremias afirma que tentou não proclamar esta palavra divina, contudo, ele não pôde prevalecer $(y \bar{a} k \bar{c} l)$. E aqui há uma mudança de percepção. Uma mudança relacionada a confiar na palavra de Deus e carregá-la. Jeremias inicia a perícope se queixando de Deus, mas quando começa a se queixar contra seus inimigos, ele tem certeza de que eles, não Deus, eram os verdadeiros inimigos.

\section{Conclusão}

A violência faz parte da retórica de Jeremias. Todavia, de forma alguma o livro estimula a violência. Pelo contrário, o surgimento da violência divina é um convite à cessação dessa violência. Deus havia feito uma aliança com Israel e agora estavam sendo infiéis. Como resultado, Deus traria uma outra nação que os levaria ao exílio.

Com uma retórica forte, Jeremias apresenta um Deus a quem devemos temer. Talvez não somente no sentido de reverência, respeito e obediência. Mas também de medo. Ao longo do lamento a ideia apresentada por Jeremias parece clara: Ao temer a Deus, Israel tem medo da "coisa certa", e por conta disso, paradoxalmente, não deve temer mais nada.

\section{Referências}

ALLEN, L. C. Jeremiah: A Commentary. Louisville, KY: Westminster John Knox Press, 2008.

AVIOZ, M. The Call for Revenge in Jeremiah's Complaints (Jer XI-XX). Vetus Testamentum, v. 55, Fasc. 4, p. 429-438, Oct., 2005.

BAUMGARTNER, W. Die Klagegedichte des Jeremia (BZAW, 32). Giessen: A. Töpelmann, 1917.

BAUMGARTNER, W. Jeremiah's Poems of Lament. New York, NY: Bloomsbury Academic, 2015.

BLENKINSOPP, J. A History of Prophecy in Israel. Louisville, KY: Westminster John Knox Press, 1996.

BROYLES, C. C. The conflict of Faith and experience in the Psalms. Sheffield: Sheffield Academic Press, 1988.

BRUEGGEMANN, W. The theology of the book of Jeremiah. New York, NY: Cambridge University Press, 2007.

CLINES, D. J. A.; GUNN, D. M. Form, Occasion and Redaction in Jer 20. ZAW 88: p. 390-409, 1976.

CLINES, D. J. A.; GUNN, D. M. "You tried to persuade Me" and “Violence! Outage!” in Jeremiah XX 7-8, VT 28:20-27, 1978.

DAVIS, Ellen F. Biblical Prophecy. Louisville, KY: WJK, 2014. 


\section{Arquivo Maaravi}

Revista Digital de Estudos Judaicos da UFMG

ISSN: 1982-3053

DIAMOND, A. R. P. The Confessions of Jeremiah in Context (JSOTSup, 45). Sheffield: JSOT Press, 1987.

DIAMOND, A. R. P. Jeremiah's Confessions in the LXX and MT: A Witness to Developing Canonical Function?, VT 40: 33-50.

JOHNSTON, P. S. “'Now you see me, now you don't' Jeremiah and God". Prophecy and the Prophets in Ancient Israel. John Day (Ed.). New York, NY: Bloomsbury, 2014.

KALMANOFSKY, Amy. Terror All Around: Horror, Monsters, and Theology in the Book of Jeremiah (Library of Hebrew Bible/Old Testament Studies 390). London/New York: T\&T Clark, 2008.

O'CONNOR, Kathleen M. “Reclaiming Jeremiah's Violence. The Aesthetics of Violence in the Prophets. Chris Franke e Julia M. O'Brien (Ed.). New York, NY: T\&T Clark International, 2010. p. 37-49.

O'CONNOR, Kathleen M. "The Tears of God and Divine Character in Jeremiah 2-9". Troubling Jeremiah, A. R. P. Diamond, Kathleen M. O'Connor e Louis Stulman (Ed.). Sheffield: Sheffield Academic Press, 1999. p. 387-403.

PEELS, E. "Jeremiah, Prophet of Ultimate Ruin and New Hope". The Lion has Roared: Theological themes in the Prophetic Literature of the Old Testament H.G.L Peels e S. D. Snyman (Ed.). Eugene, OR: Pickwick Publications, 2012. p. 96-118.

SEITZ, C. R. Theology in Conflict. Berlin: W. De Gruyter, 1989.

SWEENEY, M. Reading the Hebrew Bible after the Shoah. Minneapolis, MN: Fortress, 2008.

SWEENEY, M. Tanak: A Theological and Critical Introduction to the Jewish Bible. Minneapolis, MN: Fortress Press, 2012.

THOMPSON, J. A. The book of Jeremiah. Grand Rapids, MI: Eerdmans Publishing Co., 1980.

Recebido em: 09/03/2018.

Aprovado em: 09/04/2017. 